\title{
BMJ
}

\section{Exploring preferences for place of death with terminally ill patients: qualitative study of experiences of general practitioners and community nurses in England}

\author{
Daniel Munday, associate clinical professor in palliative medicine, Mila Petrova, research fellow, Jeremy Dale, \\ professor of primary care
}

Health Sciences Research Institute, Warwick Medical School, University of Warwick, Coventry CV4 7AL Correspondence to: D Munday d.munday@warwick.ac.uk

Cite this as: BMJ 2009;338:b2391 doi:10.1136/bmj.b2391

\section{ABSTRACT}

Objective To explore the experiences and perceptions of general practitioners and community nurses in discussing preferences for place of death with terminally ill patients. Design Qualitative study using semistructured interviews and thematic analysis.

Participants 17 general practitioners and 19 nurses (16 district nurses, three clinical nurse specialists).

Setting 15 general practices participating in the Gold Standards Framework for palliative care from three areas in central England with differing socio-geography.

Practices were selected on the basis of size and level of adoption of the standards framework.

Results All interviewees bar one had experience of discussing preferred place of death with terminally ill patients. They reported that preferences for place of death frequently changed over time and were often ill defined or poorly formed in patients' minds. Preferences were often described as being co-created in discussion with the patient or, conversely, inferred by the health professional without direct questioning or receiving a definitive answer from the patient. This inherent uncertainty challenged the practicability, usefulness, and value of recording a

definitive preference. The extent to which the assessment of enabling such preferences can be used as a proxy for the effectiveness of palliative care delivery is also limited by this uncertainty. Generally, interviewees did not find discussing preferred place of death an easy area of practice, unless the patient broached the subject or led the discussions.

Conclusions Further research is needed to enable development of appropriate training and support for primary care professionals. Better understanding of the importance of place of death to patients and their carers is also needed.

\section{INTRODUCTION}

The recent publication of the End of Life Care Strategy for England has highlighted the importance of enabling patients to express preferences regarding end of life care and for recording these wishes in an advance care plan. ${ }^{12}$ Such choices could include patients' preferences on the continuation of active treatment and whom they might like to make decisions on their behalf if they lacked the mental capacity. ${ }^{3} \mathrm{~A}$ central aspect of choice concerns patients' preference for place of death. This is an important aspect of patient autonomy but is likely to be influenced by several factors, such as the uncertainty of prognosis, ${ }^{45}$ the fact that active treatment is being offered increasingly late in life ${ }^{6}$ and the complexities of delivering effective care at this time.

Numerous studies have suggested that home death is the most common choice patients express, ${ }^{78}$ but that this preference becomes less pronounced as death approaches. ${ }^{910}$ In addition, patients often demonstrate an inclination towards one choice or another rather than express a preference in categorical terms. ${ }^{11}$ Preferences around place of death thus seem fluid and are challenging to elicit and record. Primary care professionals, in particular general practitioners and generalist (district) nurses, have an ongoing therapeutic relationship with the patient and their family and are particularly well placed to take a central role in this sensitive process. Palliative care clinical nurse specialists - who are frequently involved in caring for patients in the community approaching the end of life and provide support and advice for general practitioners and district nurses - are also often involved in eliciting patient preferences. ${ }^{12}$

Recent UK programmes for end of life care have encouraged primary care professionals to seek out patient preferences for place of death and have achieved some success in increasing recording and enabling of these preferences. ${ }^{13-16}$ The most prominent of these programmes, the Gold Standards Framework, aims to enable general practitioners and community nurses to optimise practice in palliative and end of life care. The framework provides guidance through workshops and by supporting locally based health professionals who facilitate a group of practices in establishing the clinical and organisational processes needed to enable such care. The framework is also supported by a plethora of practical tools, guidance documents and examples of good practice available on a central website. ${ }^{1417}$ Moreover, since 2006 general 
practitioners in the UK have been financially rewarded for having a register of patients at the end of life, in which patients' preference should be recorded. ${ }^{18}$ More than $90 \%$ of general practices achieved this target in the first year following implementation. ${ }^{19}$

On the other hand, little is known about how primary care professionals undertake sensitive discussions about patient preferences at the end of life. ${ }^{20} \mathrm{In}$ this paper, we describe general practitioners' and community nurses' perceptions and experiences of exploring patients' preferred place of death. All participants were working in practices enrolled in the Gold Standards Framework for palliative care and this study forms part of the wider evaluation of the framework. ${ }^{162122}$

\section{METHODS}

We analysed subsections of interviews undertaken to explore the effectiveness and sustainability of the Gold Standards Framework in participating practices. Questions concerning the health professionals' approach to and experiences of discussing preferred place of death (box 1) were included within the wider interview schedule (methods of data collection have been described fully elsewhere). ${ }^{162122}$ Semistructured interviews were performed and observational data were collected from 15 participating practices in three areas with different socio-geography. Practices were sampled purposively and visited between October 2005 and March 2006. A total of 36 interviews were carried out -17 with general practitioners and 19 with community nurses (16 district nurses and three clinical nurse specialists in palliative care). All interviews were audio recorded and fully transcribed apart from one interview with a general practitioner and one with a district nurse. This district nurse interview did not cover the issue of preferred place of death and thus was excluded from analysis. All interviewees were experienced professionals and were selected because of their particular involvement in the implementation of the Gold Standards Framework and the delivery of palliative care within their practice.

Each practice had also completed serial questionnaires as part of the wider evaluation of the 1300 practices taking part in Gold Standards Framework. ${ }^{1621}$ The responses to these questionnaires enabled a comparison between participants' experiences of discussing preferred place of death and the level of adoption of the framework at the particular practice.

Data analysis was undertaken using a broadly realist theoretical approach. ${ }^{23}$ Two researchers (MP and Steven Martin (see acknowledgments)) independently coded 10 interviews for major themes. using an inductive constant comparative method and NVivo 7 software (QSR International Pty Ltd; Doncaster, Victoria, Australia). Six of the interviews were coded by both researchers and the remaining four were randomly selected by each coder. Coding frameworks and assignments were then discussed and an overarching coding framework established. As there was substantial agreement between the two coders in terms of major themes identified, one researcher (MP) completed the coding of the remaining 26 interviews. Codes were refined by clarifying their coverage and boundaries, adding subthemes, and increasing the number of categories to cover different perspectives on the same theme. Relevant statements were coded with ample context to avoid data fragmentation and decontextualisation. ${ }^{24}$ No new topics were identified following analysis of approximately two thirds of the interviews; however, all interviews were coded in order to develop a better understanding of how characteristic the views and reported behaviours were, and also to collect further examples of unusual/ deviant observations.

The thematic analysis was supplemented with a framework analysis to further explore the relationships between emergent themes and issues relevant to clinical practice in palliative care (such as the relationship between an interviewee's approach to discussing preferred place of death, their professional background, and the level of their practice's adoption of the framework). ${ }^{24}$ As no clear relationships were discovered, this aspect of the analysis is only briefly reported.

\section{RESULTS}

Four main themes concerning preferences for place of death were identified: the nature of preferences; how they were identified; how they were recorded; and how they were achieved.

\section{Nature of preferences for place of death}

The strongest message conveyed by the interviewees was that they considered place of death preferences as typically dynamic and/or incompletely defined. Preferences evolved, sometimes rapidly, with progression towards the final days of life, or could be vague or only partially formed. Some patients had clear preferences (for example, "definitely wanted to die at home, absolutely," "adamant that she was dying at home," "desperately wanted to stay at home") that were unchanged until their last hour, but such certainty did not seem to be typical in the participants' experience.

\section{Preferences evolve and can change}

The most widely reported change was a reversal of the preference for dying at home owing to the patient experiencing distressing symptoms, becoming frightened, feeling vulnerable, or becoming concerned for his or her family. There was also a tendency for patients to replace the previously expressed preference to die at a specific place (for example, home or hospice) with a desire to remain at the place where they were currently being cared for.

"[H]e was very open, you know, said from the start he wanted to die at home. That's what it was but then to the end he said, 'I can't let my family go through this anymore. I can't let them suffer the distress of seeing me like this.' . . . and said, 'get me into the hospice. I don't want my family to see me in this'." (district nurse 12 , practice I) 


\section{Box 1 Questions regarding preferred place of death from wider interview schedule}

The first set of questions covers broad topics related to preferred place of death. The second set of questions includes examples of prompts and probing questions that were used selectively in response to cues from the interviewees' answers.

\section{Broad topics questions}

What do you think of the idea of getting patients to talk about preferred place of death? Do you ask patients about their preferred place of death and how do you go about this? Are there any situations where preferred place of death wouldn't be discussed? Why not if there are?

Who brings up the topic of preferred place of death?

How does discussing preferred place of death with patients make you and your colleagues feel?

Are these preferences recorded and, if so, when?

Can you give me a recent or memorable example where you felt preferred place of death was dealt with well? Can you give me an example where you felt less satisfied?

\section{Examples of prompts and probing questions}

How frequently do you think patients' preferences should be checked [if you say they are changing]?

If the patient changed their mind, would it be documented?

How do you define appropriate [moment for asking about preferred place of death]?

How do you take cues from the patient about when and if to discuss preferred place of death?

How long would you say you need to be acquainted with the patient for them to even start bringing up issues about where they're going to die?

Do patients ever bring up [preferred place of death]?

How do you actually deal with patients who don't want to discuss [preferred place of death]?

Do you feel that there's enough training?

What do you do when a patient's wishes are different from those of their carers and families?

Do you ever think about whether you have any inhibitions about discussing [preferred place of death] with [patients]?

"[A]nd then she turned around and she said, 'you know, I wouldn't mind dying here [hospice]'. And I said, 'Oh, are you sure, because you wanted to die at home?' 'No,' she said, 'I think this is a lovely place, the staff are so friendly'." (general practitioner 15 , practice J)

Some interviewees identified a particular situation where it was difficult to assert whether the patient died at their preferred place or not. These patients acknowledged that "reality" was incompatible with their preference-for instance, their local services or support networks had limited capacity; or they accommodated competing preferences and desires, such as their own desire not to be an excessive burden to their families - and made the choice to go to a different place. They "agreed," "didn't insist," "did it for their family".

"[S]he actually in the end was able to express a preference to go into the hospice . . but then she was a delightful and very unselfish sort of person who, I think, just recognised when it was just becoming unmanageable and didn't insist." (general practitioner 16 , practice $\mathrm{K}$ )
"He had got mesothelioma and [was] very poorly, went down very quickly, and she wanted him in a hospice because she just couldn't cope ... And he agreed reluctantly in the end ... She just could not manage him and it wasn't fair ... I think it was done on the basis that, you know ... she's finding it difficult and to cope and he did it for her.” (district nurse 4, practice C)

\section{Preferences can be ill defined or their formation blocked}

Some preferences could also be seen as relatively weak; that is, only a leaning in one direction or another rather than indicating a definitive wish.

"[A]nd they will say, 'Well, I'd rather be at home with my dear ones' or 'I'd rather be in a hospice and not cause stress at all' ... so you can't always get a yes/ no answer in these kind of situations." (general practitioner 14, practice I)

More extreme cases were reported in which patients experienced their terminal illness in a way that precluded the formation or identification of a preference for place of death. This way of relating to approaching death was construed in various forms: as denial, as a different way of coping (for example, "they will fight till the end"), as a consequence of misunderstanding the prognosis, or, very rarely, as a consequence of being misled about the prognosis. Discussing preferences for end of life care with such patients was felt to be difficult, impossible, or unethical.

\section{Identifying preferences for place of death Techniques for identifying preferences}

Various ways of eliciting preferred place of death were described by interviewees. For the purpose of recording a patient's preference, "ideal" situations were those in which the patient was explicit about their preference, either having volunteered the information or having been skilfully guided and supported by the health professional towards expressing their preference. The interviewees believed, however, that valuable and valid information about place of care at the end of life was more often gained in less explicit ways, with source, situation, communication skills, and experience interacting in a complex way.

In straightforward situations, patients stated clearly where they would prefer to be cared for or "opened a door" to the discussion by acknowledging that they were dying.

"[A] significant number of times, I guess, patients will actually say directly to you, 'look, I'm quite ill, I know I'm quite ill, the one thing I'd really like is to be looked after here because I'm quite comfortable here'. And we'll have that discussion." (general practitioner 5, practice $\mathrm{C}$ )

"[I]f they were to say, 'well, I know I'm going to die', then they have sort of opened up the door and I can follow on with that, and that's an easy task." (district nurse 5 , practice $\mathrm{D}$ ) 
If the patient did not bring up the issue in a very direct way, the discussions were described as being more subtle, using euphemistic vocabulary, and relying much more on giving, picking up, and interpreting cues - on sensing the "vibes" of the conversation and the situation. Interviewees felt that in many cases it seemed indisputable that the patient understood the underlying issue being raised; "[they knew] exactly what you're talking about" and "you know exactly what they are asking" (district nurse 8, practice E). In other cases, verbalisation was even more limited, yet accumulating cues from the patient, context, or relatives were interpreted as conferring a valid preference. Recording a clear preference in these situations was, therefore, problematic. In other cases, the tendency to rely predominantly on indirect sources of information (for example, behavioural cues and carers' reports) seemed closely associated with the health professional experiencing difficulties in having the discussion about end of life care.

"I don't ask them their preferred place of death. I'd ask them, 'how are you managing, how are you getting on, is there anything...?' If you go in a home situation you read the signs, you read the body language of the relative, of the carers as well, and also other people who are going in to help that patient." (general practitioner 17 , practice $\mathrm{M}$ )

"Yes, very rarely they'll say 'I want to die at home.' It's always 'when I can't cope any more and I can't go to the toilet on my own,' 'I don't want the children to see me like this.' These are terms that they will use." (district nurse 7 , practice $\mathrm{D}$ )

\section{Times when discussing preferred place of death becomes inappropriate}

Most interviewees could recall patients with whom they had found it extremely difficult or impossible, unethical, or potentially damaging to the doctor-patient relationship to discuss preferred place of death. Attempts were either not made or quickly abandoned. This situation was almost invariably attributed to the patient being "in denial". Only one interviewee admitted that the primary reason for having not discussed preferred place of death with "difficult patients" might be the professional's own capacity to approach such situations.

"[U]ndoubtedly, there are some people who need to keep going by denial and, you know, they don't want to talk about it." (general practitioner 10, practice E)

"I think a lot of patients that we go in to haven't psychologically accepted that they are going to die. And to then start to talk about place of death puts up the barriers, and we're a guest in their home, and that relationship can so easily be destroyed . . . I don't know if that's because ... maybe it's because it's something we feel uncomfortable with, and maybe we're actually doing the patients down, and [they] would quite happily talk about it." (district nurse 3, practice B)
In other cases, interviewees felt that discussing preferences was primarily unethical and, as a consequence, difficult, such as when the patient's attitude was construed as one driven by hope, rather than denial.

"You've received the referral saying that, you know, it's purely palliative treatment that they're having ... [but] the patient's convinced that the treatment ... is going to make them better and they're not going to die. So in those situations you wouldn't dream of talking to them about where they want to die." (district nurse 12 , practice I)

"But some people won't admit that they are going to die, see. It's difficult to stop people's hope . . . and I still think if somebody thinks that they are going to get through this, I don't think it was really up to me to say no you're not, you know, I find that still difficult, and it does destroy hope.” (district nurse 11, practice $\mathrm{H}$ )

\section{Co-constructing place of death preferences}

Not infrequently, interviewees believed that their professional opinion of what would be best for a particular patient differed from the patient's preference, or they were aware that the patient's desire would be difficult or impossible to accommodate. Interviewees then described engaging more actively in influencing preferences or managing the patient's expectations. A small number of interviewees described attempts to mediate between patients and carers with conflicting preferences.

"[O]ccasionally you do have someone that wants to die at home and it's not appropriate ... and you then have to say to them, 'well, look, we will try [to accommodate] your wishes as best as we can, but if at any stage you need more care than we can give, that's when we'll need to think about going somewhere else'." (general practitioner 15 , practice $\mathrm{J}$ )

"[S]ometimes if you've got an old lady and she has absolutely no relatives at all, and there might be a 90 year old neighbour who pops in, and she says, 'no, my neighbour will do it, it's alright, my neighbour will do that.' You have to say, 'well, actually, she can't, we think we ought to think about something else'." (district nurse 14, practice M)

Descriptions of crisis situations demonstrated the decisive role that health professionals can play in preference formation. In crisis situations, earlier preferences tended to disintegrate and patients were often unable to form or communicate new ones. Preferences were felt to no longer be an issue for patients and carers and were substituted by expectations that a professional judgment be made. A few interviewees described an approach by which they helped the patient and family put together an explicit new preference. In the remaining cases, it was unclear whether a preference was actively deduced on the basis of behavioural and situational cues and on previous 
experience of such a situation, or whether preference was determined only intuitively and thus was likely to be over-ridden by professional judgement.

\footnotetext{
"[A]nd that would be a crisis situation where you would say, 'OK, what do you want to do here, shall we continue trying to get this sorted at home or would you want to look at going into the hospice or hospital?"” (clinical nurse specialist 2, practice F)

"And that's probably something you don't actually verbalise with them. But in the crisis situation, for whatever reason, they feel better and more secure to then go and die in hospice or hospital." (district nurse 3 , practice $\mathrm{B})$
}

\section{Primary care professionals' feelings on discussing preferred place of death}

Only one interviewee mentioned never having discussed preferred place of death. None of the remainder described difficulty if the discussion was broached by the patient.

"[M]aybe I am inhibited to ask people, but I'm not inhibited to if they instigate it, I'm quite happy to talk about it with them, and to tell them what alternatives are available to them and what care would be available for them if they choose to stay at home. So I'm quite happy to talk about it when they are happy to talk about it." (district nurse 7, practice D)

Interviewees varied widely in how they felt about initiating the discussion themselves.

The interviewees' feelings when they perceived a need for preferred place of death to be discussed but the patient had not initiated a discussion ranged on a continuum between two extremes. Most typically, the health professionals distinguished between easy and more difficult situations on the basis of the patient's personality, acceptance, and response; the relationship formed with them; and/or contingent situational factors (for example, the "timing" of the discussion).

\footnotetext{
"It very much depends on the person and your relationship, and how you've actually managed to communicate with them. So, it very much depends." (clinical nurse specialist 2, practice $\mathrm{F}$ )

"I don't feel uncomfortable with it really. I mean, once one's built up a good relationship and can be honest with the patient, you know, once the patient is ready to accept that they are going to die and so on ... once the time is right, I don't feel uncomfortable discussing it." (general practitioner 9, practice $\mathrm{E}$ )
}

One interviewee (a clinical nurse specialist) suggested that sometimes discussing preferred place of death could actually make the interviewee feel good and make them feel that "you've achieved something ... you've actually reached a very deep level and a deep understanding and trust for them to be able to talk to you at that level" (clinical nurse specialist 2, practice $\mathrm{F}$ ).
A few interviewees did not make distinctions between easy and more difficult cases and found raising the issue generally not easy, not pleasant, or outright difficult.

"Slightly uncomfortable, you know . . . [I]t's one of those things that you know you've got to do and you know you've got to say it and like. I feel better once I've done it. I'm always nervous doing it." (district nurse 1 , practice $\mathrm{A}$ )

"Me personally? I find it very difficult, still. I think the nurses, it's an easy cop-out to say the nurses are much better at it ... if you're going in for a fairly short visit, it's sometimes a lot more difficult to get round to place of death and fears about the actual process of dying." (general practitioner 10 , practice $\mathrm{E}$ )

“[I]t's not a favourite one. I must admit sometimes ... I chicken out and leave it for [the home care teams] to do because I know it's one of the questions that they'll ask when they do their assessment. And then the next time I go in I might feel a bit braver and ask . . . And it's easier then because somebody else has already broached the subject with them." (district nurse 12, practice I)

Finally, a small group of interviewees (three general practitioners who had described little or no involvement in discussing preferred place of death and a very experienced district nurse) denied any difficulty in having the discussion.

"No problem, I think it helps to, if you think it is an issue then to resolve that issue I think is fine, it makes everybody feel more comfortable with where we're going." (general practitioner 6, practice $\mathrm{C}$ )

Interviewees varied in the extent to which they saw themselves as involved in discussions about preferred place of death in comparison with other members of the team. They often thought that such discussions were primarily held by a colleague with a different professional role - the general practitioners most often pointed to the district nurses, and the district nurses to the clinical nurse specialists in palliative care. These other professionals were seen as better trained or better positioned to discuss preferred place of death owing to, for instance, the intense personal contact and longer time spent with the patient. Some interviewees believed that all members of the team discussed the topic to a similar extent. Few saw themselves as taking the greatest share of the responsibility. The perceptions of members of the same team did not always coincide; for example, in two practices the nurses believed that everybody discussed the topic with patients to a similar extent, whereas the general practitioners in the same practice felt that it was usually the nurses who discussed preferred place of death. No clear pattern was identified between an interviewee's involvement and their experiences of discussing preferred place of death, their professional background, and the extent of their practice's adoption of the Gold Standards Framework. 
Recording and auditing preferences for place of death Interviewees focused on their concerns with regard to recording preferred place of death rather than the benefits. The benefits - improved communication, protection against unplanned hospital admissions, and increased likelihood of having the discussion-were, however, greatly valued by those who mentioned them.

The main concern identified was a direct consequence of the complexity of preference formation and identification, which translated into difficulty recording. In turn, it was felt that this difficulty undermined the usefulness, practicability, and fairness of evaluations of quality of care using such records. Occasionally, it was considered appropriate to change records post-factum so that audit figures were fairer.

\footnotetext{
"[N]ow if by saying they're prepared to go into a hospice, are they saying their preferred place of death is a hospice or is their preferred place of death still home, but they are realising that, basically, that is not possible, therefore they are making a choice to go into a hospice although that's not their preference?" (general practitioner 17 , practice $\mathrm{M}$ )

"[A]t what point do you record it? Five minutes before they die when they actually don't want to be moved? Or, a week ago when they said, 'no, I want to be in hospital, it's too much trouble for my wife'? Or, in the middle when they haven't got consciousness so they can't make a decision?" (district nurse 8, practice E)
}

\section{Box 2 Constraints to enabling patients to die at their preferred place}

Constraints arising from the social support network (when the preference is for a home death)

- Conflict of preferences and/or perceived inability of the carer(s) to cope-particularly likely in patients who have small support network, an elderly carer and/or a carer whose own health is poor, or longstanding issues of negative family dynamics

- Social system collapse owing to the carer(s) experiencing events as being more difficult and frightening than expected and/or becoming physically and emotionally exhausted

- Situations in which the carer finds it impossible not to request active intervention-for example, when they cannot bear to watch a loved one suffer

Constraints arising from service limitations

- Difficulty providing 24-hour care (primarily nursing care and night sitters)

- Very limited availability of hospice beds

- Limited services for carers-for example, opportunities for counselling or respite

Constraints relating to symptom control and the avoidance of unnecessary suffering

- Situations in which keeping the patient at home would make it impossible to achieve optimum symptom control

- Situations in which moving the patient to their preferred place would be more likely to cause unnecessary suffering than result in a "better" death

Constraints relating to the ultimate unpredictability of the precise moment of dying Patients might die at a non-preferred place in which they were being cared for temporarily because they were:

- Admitted for symptom control or respite

- Awaiting a hospice bed
Some interviewees were also apprehensive about potential deviations from good practice. One such concern related to the possibility that preferences for place of care are forced on to patients, either by "badgering" them to identify a preference or by "shoehorning" them into a place where they no longer desired to be. Some interviewees also feared that too strong an emphasis on identifying place of care could numb sensitivity, distort priorities, and betray the true purpose of the discussion.

"[S]he [a clinical nurse specialist] had to practically badger this patient to tell her where they wanted to die, and I felt it was inappropriate and unnecessary, when the lady said she wanted to stay at home, she was almost forcing saying, 'Oh, I want to die at home'.” (district nurse 7, practice D)

"There might be something else that's really on their mind, you know, that they'd really like to be talking about and you're sitting there thinking, 'I really need to find out where this person would like to die'." (district nurse 6 , practice $\mathrm{D}$ )

Constraints to enabling patients to die at their preferred place

The constraints to enabling patients to die at their preferred place relate to contingent factors or wider issues (for example, family capacity or service availability). Box 2 presents schematically the constraints to achieving preferred place of death, even when the preference has been stable and clearly identified. These constraints were often discussed - with overtones of frustration and a perceived need to self-defend - as factors that were not fully recognised when assessing a practice's performance in enabling its patients to die at their preferred place.

\section{DISCUSSION}

\section{Principal findings}

This study reports on the experiences of general practitioners and community nurses in eliciting, recording, and enabling preferred place of death. Most interviewees reported that they did not find discussing preferred place of death an easy area of practice. General practitioners and community nurses described how they balanced the imperative given in guidelines to elicit preferred place of death with assessment of the appropriateness of discussing the issue with patients. Although the primary care professionals participating in this study felt that they resisted the impulse to record preferences in a "tick box fashion," they were concerned that other colleagues might be less reflective and coerce patients into unwanted discussions. Some interviewees described how they responded to cues to open up relevant discussions, and how they might need to interpret a patient's preference from general discourse without coming to a definitive answer to the question "where would you like to be when you are dying?" Other interviewees described how in some situations they might be directly involved in 
negotiating plans with the patient and their family so that the eventual stated preference was co-created. All participants discussed how they needed to draw on considerable skill in communication and to devote time to the process.

Interviewees also reported that even if a firm preference for place of death was established, a rapidly changing clinical situation at the end of life and contingent factors - such as where the best care might be offered, the presence or lack of a social support network, and the availability of services - affected the likelihood of preferences being realised. These factors might even alter the patient's previously strongly held preference. These issues form a complex and interacting network of factors that make eventual outcome far from certain.

\section{Comparison with other research}

Factors that have previously been shown to be associated with home death-in particular living with family and the presence of an extended social support system - were evident from the experiences discussed by participants in this study. ${ }^{25}$ Our findings also support those of previous studies, which reported that although patients and their families might express a strong preference for a home death, the burden of caring and fears arising from the uncontrolled nature of the dying process or having a death occurring in the home might lead to hospital admission as death approaches. ${ }^{26-28}$

High quality end of life care is dependent on the communication skills of the healthcare professional..$^{2930}$ Training in communication skills is likely to be important ${ }^{3132}$; however, inclusion of specific palliative care training in general practitioner vocational training schemes varies widely. ${ }^{33}$ Moreover, general practitioners seem to identify training in technical aspects of symptom control as a more important element of palliative care education than communication training. ${ }^{34}$ Similarly, although palliative and end of life care is central to the district nurses' role ${ }^{35}$ they do not always feel adequately trained, particularly in areas of symptom control. ${ }^{3637}$ Training in palliative care might increase district nurses' confidence in communicating with patients and carers. $^{38}$

Many participants highlighted the importance of an ongoing supportive relationship with patients. This issue accords with the needs of patients with life limiting illnesses and their carers, who express the desire for ready access to a familiar healthcare professional who will take time to discuss and explain care issues. ${ }^{3940}$ Bereaved carers express a high degree of satisfaction when this approach has been taken. ${ }^{412}$ In addition, carers of patients who died in their preferred place express higher satisfaction with general practitioners than carers of patients who did not. ${ }^{43}$ Whether this satisfaction with general practitioners is a direct result of fulfilling preferences or reflects a broader satisfaction with the supportive approach that enabled preferences to be achieved is unclear.

We are unaware of any other studies into how preferences for place of care at the time of death are elicited by primary care professionals in the community. This study underlines how determining preferences is a complex mix of direct questioning and looking for cues and general leanings. The danger of an indirect approach is that assumptions about a patient's preference could be made or that the issue is avoided because of concerns over not being able to fulfil the patient's expectations. Previous research has indicated that some general practitioners might avoid exploring psychosocial issues with patients, ${ }^{44}$ and that general practitioners and district nurses might avoid discussing symptom control issues if they are not familiar with the appropriate management. ${ }^{45}$ Failing to explore difficult issues might also disadvantage carers, who have reported that they frequently have unanswered questions because staff have not given them the opportunity to discuss areas of concern. ${ }^{46}$

Finally, although much research has explored patients' preferences for place of death, ${ }^{7}$ very little has explored the importance of place of death to patients. Steinhauser et al reported that achieving a home death was not as important to patients as other factors such as freedom from pain, having family present, having treatment choices followed, feeling life was meaningful, and resolving conflicts. ${ }^{47}$ More research needs to be undertaken to explore the importance patients attach to choosing place of death in order to prevent practice being driven by policy rather than patient need.

\section{Strengths and limitations of the study}

This study used rich data provided by a relatively large sample of expert informants on an important but under-researched topic. The context in which the data were obtained is one of the study's strengths, but also its main limitation. The interviews were collected for the purpose of evaluating the national Gold Standards Framework programme. The interviewees were in practices that were early adopters of the programme and are thus likely to have had more than average knowledge and interest in palliative care. This factor might have produced a particularly insightful picture of the nature of preferences for care at the end of life that may not be representative of primary care in the UK. Further research with late adopters and in healthcare settings in other countries would make a valuable addition to this study.

Furthermore, in this study, participants were not explicitly asked about their approach to discussing the issue of preferred place of death with patients from different ethnic and cultural groups. Recent research has illustrated how patients' perceptions and attitudes at the end of life can vary widely between different ethnic and cultural groups, but also across generations within one group. ${ }^{48}$ This cultural aspect should be explored in further research in different ethnic and cultural settings.

A further limitation, as far as achieving a balanced picture is concerned, arises from a bias towards negativity in the views presented. The Gold Standards Framework places strong emphasis upon and has 


\section{WHAT IS ALREADY KNOWN ON THIS TOPIC}

Home death has been identified as the most common preference expressed by patients at the end of their life. Preferences for place of death can, however, change over time or be poorly formed

Discussing, eliciting, and recording preferred place of death has been identified as an important aspect of palliative care and is encouraged in England in the recent End of Life Care Strategy

Little previous research has reported on the experiences of primary care professionals in addressing this issue

\section{WHAT THIS STUDY ADDS}

This study explores the perceptions and experiences of general practitioners and nurses in eliciting place of death preferences and in enabling patients to die at their preferred place

The results offer insights into the complex nature of these preferences, the constraints to eliciting and acting on them, and the implications for auditing, quality assessment, and training of primary care professionals
Competing interests: DM and JD received a grant from Macmillan Cancer Support to evaluate phases 3-6 of the Gold Standards Framework and are members of the Macmillan Primary Care Research Collaborative. The post of MP has been partially funded by Macmillan Cancer Support. Ethical approval: Multicentre Research Ethics Committee approval; ref 05/Q2803/48

1 Department of Health. End of Life Care Strategy. London: Department of Health, 2008.

2 Murray S, Sheikh A, Thomas K. Advance care planning in primary care. BMJ 2006;333:868-9.

3 Munday D, Maher E. Informed consent and palliative chemotherapy. BMJ 2008;337:a868.

4 Glare P, Virik K, Jones M, et al. A systematic review of physicians' survival predictions in terminally ill cancer patients. $B M$ J 2003;327:195-201.

5 Fox E, Landrum-McNiff K, Zhong Z, Dawson NV, Wu AW, Lynn J. Evaluation of prognostic criteria for determining hospice eligibility in patients with advanced lung, heart, or liver disease. JAMA 1999;282:1638-45.

6 Earle CC, Neville BA, Landrum M, Ayanian JZ, Block SD, Weeks JC Trends in the aggressiveness of cancer care near the end of life. J Clin Oncol 2004;22:315-21.

7 Higginson I, Sen-Gupta. Place of care in advanced cancer: A qualitative systematic literature review of patient preferences. J Palliat Med 2000;3:287-300.

high expectations for discussing preferred place of death. In contrast, the interviewees focused on the difficulties associated with the concept of preferred place of death rather than on its value. Thus, the responses might need to be interpreted as balancing an enthusiastically promoted view rather than describing practitioners' complete view of the issue.

\section{Conclusion}

Determining preferred place of death has become a central aspect of end of life care. Practices in the UK are rewarded for having a register of palliative care patients, meeting regularly to discuss patients' needs, and recording their preferred place of death. Enabling patients to express their preferences and to ultimately achieve them is a complex process that demands a compassionate and skilful approach over time to allow preferences to be determined "in the moment". This study illustrates how primary care professionals who have ongoing relationships with patients and their carers have an essential role in this process. Further research is needed to explore this important area of practice more fully so that appropriate training and support can be given to primary care professionals, but also in order to achieve better understanding of the importance that patients attach to achieving their preferred place of death.

We thank the participants in the study for their detailed and perceptive responses. We also thank Kashifa Mahmood-Yousuf and Shona Agarwal for doing the interviews; Steven Martin for supporting the work on coding the interviews; and Janice Koistinen for helping to improve the clarity and logic of the text.

Contributors: DM and JD jointly conceived and designed the study. Kashifa Mahmood-Yousuf and Shona Agarwal carried out the interviews. MP analysed the data and developed the interpretative framework. Steven Martin coded part of the interviews independently to compare codes and assignments with those of MP. MP and DM jointly drafted the manuscript. JD and Janice Koistinen contributed to the interpretation and prioritisation of findings, and all authors edited and agreed upon the final manuscript. DM and MP are the guarantors.

Funding: This research was funded by Macmillan Cancer Support. We declare that Macmillan Cancer Support has entrusted our research team to make all decisions associated with collecting, analysing, and interpreting data and presenting findings, and that they have not influenced this process in any way.
8 Munday D, Shipman C. Introduction: concepts, scope and models of continuity in palliative care. In: Munday D, Shipman C, editors. Continuity in palliative care: key issues and perspectives. London: RCGP, 2007.

9 Hinton J. Can home care maintain an acceptable quality of life for patients with terminal cancer and their relatives? Palliat Med 1994;8:183-96.

10 Townsend J, Frank A, Fermont D, Dyer S, Karran O, Walgrove A, et al. Terminal cancer care and patients' preference for place of death: a prospective study. BMJ 1990;301:415-7.

11 Thomas C, Morris S, Clark D. Place of death: preferences among cancer patients and their carers. Soc Sci Med 2004;58:2431-44.

12 Murray S, Boyd K, Sheikh A, Thomas K, Higginson I. Developing primary palliative care. BMJ 2004;329:1056-7.

13 Storey L, Pemberton C, Howard A, O’Donnell L. Place of death: Hobson's choice or patient choice. Cancer Nursing Practice 2003;2:33-7.

14 Munday D, Dale J. Palliative care in the community. $B M$ J 2007;334:809-10.

15 Wood J, Storey L, Clark D. Preferred place of care: an analysis of the 'first 100' patient assessments. Palliat Med 2007;21(5):449-50.

16 Dale J, Petrova M, Munday D, Koistinen-Harris J, Lall R, Thomas K. A national facilitation project to improve primary palliative care: impact of the Gold Standards Framework on process and self-ratings of quality. Qual Saf Health Care 2009;18:174-80.

17 The Gold Standards Framework: A programme for community palliative care. www.goldstandardsframework.nhs.uk.

18 Department of Health. Quality and Outcomes Framework. London:

2006. http://www.bma.org.uk/images/Quality\%20and\% 20outcomes\%20framework\%20guidance\%20-\%20Feb\% 202006 tcm41-37124.pdf (accessed 12 February 2009).

19 The Information Centre for Health and Social Care. National Quality and Outcomes Framework Statistics for 2006/2007. London: The Information Centre for Health and Social Care, 2007. http://www.ic.nhs.uk/webfiles/QOF/2006-07/QOF\% 202006-07\%20Statistical\%20Bulletin.pdf (accessed 12 February 2009).

20 Munday D, Dale J, Murray S. Choice and place of death: individual preferences, uncertainty, and the availability of care. J R Soc Med 2007;100:211-5.

21 Munday D, Mahmood K, Dale J, King N. Facilitating good process in primary palliative care: does the Gold Standards Framework enable quality performance? Fam Pract 2007;24:486-94.

22 Mahmood-Yousuf K, Munday D, Dale J, King N. Interprofessional relationships and communication in primary palliative care: impact of the Gold Standards Framework. Br J Gen Pract 2008;58:256-63.

23 Mays N, Pope C. Qualitative research in health care: assessing quality in qualitative research. BM/ 2000;320:50-2.

24 Pope C, Ziebland S, Mays N. Qualitative research in health care: Analysing qualitative data. BMJ 2000;320:114-6.

25 Gomes B, Higginson I. Factors influencing death at home in terminally ill patients with cancer: systematic review. $B M$ J 2006;332:515-21.

26 Hinton J. Which patients with terminal cancer are admitted from home care? Palliat Med 1994;8:197-210.

27 Barritt P. Care of the dying in one practice. J R Coll Gen Pract 1984;34:446-8. Department of Health, 
28 Rhodes P, Shaw S. Informal care and terminal illness. Health Soc Care Community 1999;7:39-50.

29 Faulkner A. ABC of palliative care: Communication with patients, families, and other professionals. BMJ 1998;316:130-2.

30 Wenrich MD, Curtis J, Shannon SE, Carline JD, Ambrozy DM, Ramsey PG. Communicating with dying patients within the spectrum of medical care from terminal diagnosis to death. Arch Intern Med 2001;161:868-74.

31 Barclay S, Todd CJ, Grande G, Lipscombe J. How common is medical training in palliative care? A postal survey of general practitioners. $\mathrm{Br}$ J Gen Pract 1997;47:800-5.

32 Barclay S, Wyatt P, Shore S, Finlay I, Grande G, Todd C. Caring for the dying: how well prepared are general practitioners? A questionnaire study in Wales. Palliat Med 2003;17:27-39.

33 Lloyd-Williams M, Carter Y. General practice vocational training in the UK: what teaching is given in palliative care? Palliat Med 2003;17:616-20.

34 Shipman C, Addington-Hall J, Barclay S, Briggs J, Cox I, Daniels L, et al. Educational opportunities in palliative care: what do genera practitioners want? Palliat Med 2001;15:191-6.

35 Goodman C, Knight D, Machen I, Hunt B. Emphasizing terminal care as district nurse work: a helpful strategy in a purchasing environment. J Adv Nurs 1998;28:491-8.

36 Seale C. Community nurses and the care of the dying. Soc Sci Med 1992;34:375-82.

37 Mcilfactrick S, Curran C. District nurses' perception of palliative care services: part 2. Int Journal Palliat Nurs 2000;6(1):32-8.

38 Shipman C, Burt J, Ream E, Beynon T, Richardson A, Addington-Hall J. Improving district nurses' confidence and knowledge in the principles and practice of palliative care. J Adv Nurs 2008;63:494-505.

39 Grande G, Farquhar M, Barclay S, Todd C. Valued aspects of primary palliative care: content analysis of bereaved carers' descriptions. $\mathrm{Br}$ Gen Pract 2004;54:772-8.
40 Kendall M, Boyd K, Campbell C, Cormie P, Fife S, Thomas K, et al. How do people with cancer wish to be cared for in primary care? Serial discussion groups of patients and carers. Fam Pract 2006;23:644-50.

41 Lecouturier J, Jacoby A, Bradshaw C, Lovel T, Eccles M. Lay carers' satisfaction with community palliative care: results of a postal survey. Palliat Med 1999;13:275-83.

42 Ingleton C, Morgan J, Hughes P, Noble B, Evans A, Clark D. Carer satisfaction with end-of-life care in Powys, Wales: a cross-sectional survey. Health Soc Care Community 2003;12:43-52.

43 Hanratty B. Palliative care provided by GPs: the carer's viewpoint. $\mathrm{Br}$ J Gen Pract 2000;50:653-4.

44 Kelly B, Varghese F, Burnett P, Turner J, Robertson M, Kelly P, et al. General practitioners' experiences of the psychological aspects of the care of a dying patient. Palliat Support Care 2008;6:125-31.

45 Grande G, Barclay S, Todd C). Difficulty of symptom control and general practitioners' knowledge of patients' symptoms. Pall Med 1997;11:399-406.

46 Hebert RS, Schulz R, Copeland V, Arnold RM. What questions do family caregivers want to discuss with health care providers in order to prepare for the death of a loved one? An ethnographic study of caregivers of patients at end of life. J Palliat Med 2008;11:476-83.

47 Steinhauser KE, Christakis NA, Clipp EC, McNeilly M, McIntyre L, Tulsky JA. Factors considered important at the end of life by patients, family, physicians, and other care providers. JAMA 2000;284:2476-82.

48 Worth A, Irshad T, Bhopal R, Brown D, Lawton J, Grant E, et al. Vulnerability and access to care for South Asian Sikh and Muslim patients with life limiting illness in Scotland: prospective longitudinal qualitative study. BMJ 2009;338:b183.

Accepted: 25 February 2009 